\title{
Mixed cryoglobulinemia type III
}

INSERM

\section{Source}

INSERM. (1999). Orphanet: an online rare disease and orphan drug data base. Mixed cryoglobulinemia type III. ORPHA:93555

Type III mixed cryog lobulinemia, a relatively rare clinico-serological subtype of mixed cryog lobulinemia (MC, see this term), is an immune complex disorder characterized by purpura, weakness and arthralgia and defined immunochemically by cryoglobulins containing both polyclonal IgGs and polyclonal IgMs. 